\title{
DEFORMATION RESPONSE OF GELLAN GUM BASED BONE SCAFFOLD SUBJECTED TO UNIAXIAL QUASI-STATIC LOADING
}

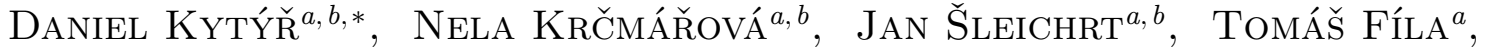 \\ Petr Koudelka ${ }^{a}$, Ana GantaR ${ }^{c, d}$, Sasa NovaK ${ }^{c, d}$ \\ ${ }^{a}$ Institute of Theoretical and Applied Mechanics AS CR, v.v.i., Prosecká 76, 19000 Prague 9, Czech Republic \\ ${ }^{b}$ Czech Technical University in Prague, Faculty of Transportation Sciences, Department of Mechanics and \\ Materials, Konviktská 20, 12000 Prague 1, Czech Republic \\ ${ }^{c}$ Department for Nanostructured Materials, Jozef Stefan Institute, Jamova cesta 39, 1000 Ljubljana, Slovenia \\ $d$ Jozef Stefan International Postgraduate School, Jamova cesta 39, 1000 Ljubljana, Slovenia \\ * corresponding author: kytyr@itam.cas.cz
}

\begin{abstract}
This study is focused on an investigation of the reinforcement effect of the bioactive glass nano-particles in the gellan gum (GG) scaffolds used in bone tissue engineering. The investigated material was synthesized as the porous spongy-like structure improved by the bioactive glass (BAG) nano-particles. Cylindrical samples were subjected to a uniaxial quasi-static loading in tension and compression. Very soft nature of the material, which makes the sample susceptible to damage, required employment of a custom designed experimental device for the mechanical testing. Moreover, as the mechanical properties are significantly influenced by testing conditions the experiment was performed using dry samples and also using samples immersed in the simulated body fluid. Material properties of the pure GG scaffold and the GG-BAG reinforced scaffold were derived from a set of tensile and compression tests under dry and simulated physiological conditions. The results are represented in the form of stress-strain curves calculated from the acquired force and displacement data.
\end{abstract}

KEYWORDS: gellan gum scaffold; reinforcement; uni-axial loading.

\section{INTRODUCTION}

The worldwide incidence of bone disorders and conditions is growing by steeply increasing trend. Particularly in the high income regions, a twofold increase between 2010 and 2020 is expected [1]. This is the tribute for populations aging coupled with improper nutrient consumption and poor physical activity. Globally, more than $40 \%$ of women and $30 \%$ of men are under increased risk of occurence of bone disorders [2]. Annually, only in the USA more than half a million bone defects are reported. The treatment expenditures reach more than $\$ 2.5$ billion per year.

Treatment of bone disorders using engineered bone tissue has been considered as a promising alternative to traditional medical treatment methods including use of autografts and allografts. Currently, the field of artificial tissue engineering represents overcoming problems, such as donor site morbidity, loss of bone inductive factors, and scaffold resorption during healing $[3$. Generally, several fundamental requirements have to be simultaneously fullfilled by the artificial tissue: i) normal cellular activity without toxicity effects, ii) minimizing of the stress shielding effect, iii) successful diffusion of nutrients and oxygen, and iv) controlled degradation coupled with the resorption of the artificial material [4].

The presented paper deals with a uni-axial quasistatic testing of the artificial spongy-like structure [5] proposed for bone tissue engineering purposes as the bone scaffold. The investigated GG-BAG material combines organic (polysacchariditic) components with inorganic (Silicon-Calcium based) nanoparticles. This approach effectively enables the adaptation of physical and mechanical properties of the synthesized material according to the desired application [6].

Mechanical properties of gellan-gums can vary significantly depending on the procedure of synthetization. Young's modulus in range $0.15-150 \mathrm{kPa}$ was reported in 7. Therefore, the newly synthesized material was subjected to the quasi-static loading in both tension and compression to evaluate primarily its stiffness and yield behaviour. Firstly, the testing was carried out under dry conditions to evaluated the material properties of the synthesized material itself. Then, the experiment was repeated under simulated physiological conditions by employment of the bioreactor with circulating synthetic plasma.

\section{Gellan-Gum BASED SCAFFoldS}

The GG-BAG material investigated in this study was synthesized at the Jozef Stefan Institute (Slovenia) as a porous spongy-like structure improved by the BAG nano-particles with size of $\approx 200 \mathrm{~nm}[8$. The GG is a microbial extracted polysaccharide used in the food and pharmaceutical industry 9, 10. It is composed of repeating units consisting of two D-glucose and one of each L-rhamnose and D-glucoronic acids [11. The main 


\begin{tabular}{ccccc}
\hline Sample & $\begin{array}{c}h \\
{[\mathrm{~mm}]}\end{array}$ & $\begin{array}{c}D_{\min } \\
{[\mathrm{mm}]}\end{array}$ & $\begin{array}{c}D_{\max } \\
{[\mathrm{mm}]}\end{array}$ & $\begin{array}{c}m \\
{[\mathrm{mg}]}\end{array}$ \\
\hline GG00 1 & 8.77 & 4.97 & 5.09 & 10.9 \\
GG00 2 & 8.73 & 5.03 & 5.04 & 10.9 \\
GG00 3 & 8.93 & 4.95 & 5.04 & 10.4 \\
GG00 4 & 9.18 & 5.01 & 5.02 & 10.5 \\
GG00 5 & 9.01 & 4.93 & 4.96 & 10.0 \\
\hline
\end{tabular}

TABLE 1. Dimensions of pure GG samples for the compression test under dry conditions.

\begin{tabular}{ccccc}
\hline Sample & $\begin{array}{c}h \\
{[\mathrm{~mm}]}\end{array}$ & $\begin{array}{c}D_{\min } \\
{[\mathrm{mm}]}\end{array}$ & $\begin{array}{c}D_{\max } \\
{[\mathrm{mm}]}\end{array}$ & $\begin{array}{c}m \\
{[\mathrm{mg}]}\end{array}$ \\
\hline GG00 1 & 8.35 & 4.94 & 4.97 & 12.0 \\
GG00 2 & 8.28 & 5.05 & 5.06 & 10.6 \\
GG00 3 & 8.23 & 5.04 & 5.11 & 10.1 \\
GG00 4 & 8.22 & 4.99 & 5.05 & 11.3 \\
GG00 5 & 8.17 & 5.08 & 5.10 & 11.4 \\
\hline
\end{tabular}

TABLE 3. Dimensions of pure GG samples for the compression test under wet conditions.

\begin{tabular}{ccccc}
\hline Sample & $\begin{array}{c}h \\
{[\mathrm{~mm}]}\end{array}$ & $\begin{array}{c}D_{\min } \\
{[\mathrm{mm}]}\end{array}$ & $\begin{array}{c}D_{\max } \\
{[\mathrm{mm}]}\end{array}$ & $\begin{array}{c}m \\
{[\mathrm{mg}]}\end{array}$ \\
\hline GG50 1 & 8.87 & 4.99 & 5.10 & 14.8 \\
GG50 2 & 9.03 & 5.09 & 5.09 & 14.5 \\
GG50 3 & 9.10 & 4.94 & 5.10 & 15.0 \\
GG50 4 & 8.80 & 5.04 & 5.06 & 14.0 \\
GG50 5 & 8.97 & 4.92 & 4.97 & 14.2 \\
\hline
\end{tabular}

TABLE 5. Dimensions of GG samples with $50 \mathrm{wt} \%$ BAG for the compression test under dry conditions.

advantage is an ability to form highly porous 3D structures, when properly cross-linked and fabricated [12. In the terms of bone regeneration characteristics, the GG is biocompatible and biodegradable, but its mechanical properties are inappropriate to bear stresses during normal movement of a patient and to enable successful bone regeneration. The material also does not promote natural bone formation. Therefore, the GG needs to be reinforced by the bioactive glass particles (BAG).

The BAG is a nano-particulate amorphous material with the chemical composition of $70 \mathrm{n} \% \mathrm{SiO}_{2}$ and $30 \mathrm{n} \% \mathrm{CaO}$, which is prepared by the modified sol-gel method. The BAG is unique since, during degradation, it can induce precipitation of hydroxyapatite formation (even in vitro) and consequently bonds toward soft and hard tissues. Therefore, the BAG particles are highly interesting for bone regeneration applications.

During the production process of the investigated GG-BAG samples, the gellan gum was dissolved in ultrapure water by heating the solution for 30 minutes at $90^{\circ} \mathrm{C}$. To the hot GG solution, a dispersion of the BAG was admixed and $0.18 \mathrm{wt} \% \mathrm{CaCl}_{2}$ was added. Kept under high temperatures, this mixture was subsequently

\begin{tabular}{lcccc}
\hline Sample & $\begin{array}{c}h \\
{[\mathrm{~mm}]}\end{array}$ & $\begin{array}{c}D_{\min } \\
{[\mathrm{mm}]}\end{array}$ & $\begin{array}{c}D_{\max } \\
{[\mathrm{mm}]}\end{array}$ & $\begin{array}{c}m \\
{[\mathrm{mg}]}\end{array}$ \\
\hline GG00 1 & 9.12 & 5.04 & 5.05 & 10.4 \\
GG00 2 & 8.92 & 4.91 & 5.00 & 10.6 \\
GG00 3 & 8.91 & 4.92 & 4.94 & 10.6 \\
GG00 4 & 8.90 & 4.94 & 5.00 & 10.7 \\
GG00 5 & 9.04 & 4.91 & 5.02 & 11.0 \\
\hline
\end{tabular}

TABle 2. Dimensions of pure GG samples for the tensile test under dry conditions.

\begin{tabular}{lcccc}
\hline Sample & $\begin{array}{c}h \\
{[\mathrm{~mm}]}\end{array}$ & $\begin{array}{c}D_{\min } \\
{[\mathrm{mm}]}\end{array}$ & $\begin{array}{c}D_{\max } \\
{[\mathrm{mm}]}\end{array}$ & $\begin{array}{c}m \\
{[\mathrm{mg}]}\end{array}$ \\
\hline GG00 1 & 8.25 & 4.96 & 5.02 & 10.6 \\
GG00 2 & 8.24 & 4.93 & 4.98 & 10.7 \\
GG00 3 & 8.21 & 4.97 & 5.01 & 10.8 \\
GG00 4 & 8.13 & 4.96 & 5.02 & 11.5 \\
GG00 5 & 8.37 & 4.99 & 5.02 & 10.1 \\
\hline
\end{tabular}

TABle 4. Dimensions of pure GG samples for the tensile test under wet conditions.

\begin{tabular}{ccccc}
\hline Sample & $\begin{array}{c}h \\
{[\mathrm{~mm}]}\end{array}$ & $\begin{array}{c}D_{\min } \\
{[\mathrm{mm}]}\end{array}$ & $\begin{array}{c}D_{\max } \\
{[\mathrm{mm}]}\end{array}$ & $\begin{array}{c}m \\
{[\mathrm{mg}]}\end{array}$ \\
\hline GG50 1 & 8.98 & 4.93 & 5.07 & 15.1 \\
GG50 2 & 8.62 & 5.06 & 5.08 & 14.4 \\
GG50 3 & 8.74 & 4.97 & 5.05 & 14.7 \\
GG50 4 & 9.09 & 4.94 & 4.95 & 14.6 \\
GG50 5 & 9.05 & 4.90 & 5.01 & 14.4 \\
\hline
\end{tabular}

TABle 6. Dimensions of GG samples with $50 \mathrm{wt} \%$ BAG for the tensile test under dry conditions.

poured into the required mould and left there to be spontaneously jellified. The weight ratio of the GG and the BAG was $1: 1$ and the final concentration of $\mathrm{CaCl}_{2}$ was $0.03 \mathrm{wt} \%$ in all samples. Such samples were frozen for 12 hours at $-80^{\circ} \mathrm{C}$ and freeze-dried for three days in a freeze dryer.

Cylindrical samples with height $h \approx 9 \mathrm{~mm}$, diameter $h \approx 5 \mathrm{~mm}$, and weight $m \approx 11 \mathrm{mg}, \approx 16 \mathrm{mg}$ and $\approx 24 \mathrm{mg}$ for the pure GG scaffold, GG-BAG reinforced scaffold with $50 \mathrm{wt} \%$ and $70 \mathrm{wt} \%$ BAG respectively were used for the testing. Dimensions are listed in detail in Tabs. 112

$\mathrm{X}$-ray microtomography imaging was performed on all three types of material. Based on reconstructed volumetric data porosity and pore size analysis was performed. Region of interest with face of inscribed square to the face of the sample and height of $75 \%$ of the sample was binarized. Using this data the porosity $67.46,61.56$, and $35.79 \%$ for pure GG, $50 \mathrm{wt} \% \mathrm{BAG}$ and $70 \mathrm{wt} \%$ BAG content samples respectively was obtained. Microstructure of the samples were irregular with closed pores (but with some broken cell-walls). Pore size was assessed from medial, lateral and frontal section of each imaged sample. The pores in shape of 


\begin{tabular}{ccccc}
\hline Sample & $\begin{array}{c}h \\
{[\mathrm{~mm}]}\end{array}$ & $\begin{array}{c}D_{\min } \\
{[\mathrm{mm}]}\end{array}$ & $\begin{array}{c}D_{\max } \\
{[\mathrm{mm}]}\end{array}$ & $\begin{array}{c}m \\
{[\mathrm{mg}]}\end{array}$ \\
\hline GG50 1 & 8.40 & 4.93 & 4.98 & 18.0 \\
GG50 2 & 8.56 & 5.07 & 5.10 & 17.7 \\
GG50 3 & 8.38 & 4.91 & 4.96 & 18.0 \\
GG50 4 & 8.24 & 4.93 & 5.01 & 16.5 \\
GG50 5 & 8.34 & 5.06 & 5.11 & 17.1 \\
\hline
\end{tabular}

TABle 7. Dimensions of GG samples with $50 \mathrm{wt} \%$ BAG for the compression test under wet conditions.

\begin{tabular}{ccccc}
\hline Sample & $\begin{array}{c}h \\
{[\mathrm{~mm}]}\end{array}$ & $\begin{array}{c}D_{\min } \\
{[\mathrm{mm}]}\end{array}$ & $\begin{array}{c}D_{\max } \\
{[\mathrm{mm}]}\end{array}$ & $\begin{array}{c}m \\
{[\mathrm{mg}]}\end{array}$ \\
\hline GG70 1 & 9.16 & 5.01 & 5.08 & 23.6 \\
GG70 2 & 9.12 & 5.00 & 5.09 & 24.4 \\
GG70 3 & 8.85 & 4.93 & 4.94 & 24.1 \\
GG70 4 & 8.88 & 5.04 & 5.05 & 24.5 \\
GG70 5 & 8.66 & 5.05 & 5.09 & 24.5 \\
\hline
\end{tabular}

TABle 9. Dimensions of GG samples with $70 \mathrm{wt} \%$ $\mathrm{BAG}$ for the compression test under dry conditions.

\begin{tabular}{ccccc}
\hline Sample & $\begin{array}{c}h \\
{[\mathrm{~mm}]}\end{array}$ & $\begin{array}{c}D_{\min } \\
{[\mathrm{mm}]}\end{array}$ & $\begin{array}{c}D_{\max } \\
{[\mathrm{mm}]}\end{array}$ & $\begin{array}{c}m \\
{[\mathrm{mg}]}\end{array}$ \\
\hline GG70 1 & 8.64 & 5.06 & 5.09 & 24.1 \\
GG70 2 & 9.10 & 4.95 & 5.02 & 24.4 \\
GG70 3 & 8.62 & 4.90 & 5.04 & 24.3 \\
GG70 4 & 9.05 & 4.95 & 4.96 & 24.4 \\
GG70 5 & 8.66 & 4.94 & 5.07 & 23.3 \\
\hline
\end{tabular}

TABle 11. Dimensions of GG samples with $70 \mathrm{wt} \%$ BAG for the compression test under wet conditions.

prolate ellipsoids were dominantly oriented in loading direction. Length of pores were $796 \pm 334,565 \pm 127$ and $429 \pm 72 \mu \mathrm{m}$ for pure GG, $50 \mathrm{wt} \% \mathrm{BAG}$ and $70 \mathrm{wt} \%$ BAG content samples respectively.

\section{Methods}

To obtain information about deformation characteristics of the synthesized material, sets of quasi-static experiments were performed. The first goal was to demonstrate possibilities of the in-house developed experimental infrastructure for such measurement. Expected collapse force ranged within single Newton orders and precise loading plate positioning was required as well. To obtain more relevant results, modifications of the experimental devices presented in detail in Section 3.2 were carried out. Then, material properties in terms of stress-strain response were obtained.

\subsection{EXPERIMENTAL PROCEDURE}

Cylindrical samples with the dimensions and weights listed in Tabs. 1,12 were subjected to tensile and compressive loading under dry and wet conditions. Here, the dry conditions represented the final state of the

\begin{tabular}{ccccc}
\hline Sample & $\begin{array}{c}h \\
{[\mathrm{~mm}]}\end{array}$ & $\begin{array}{c}D_{\min } \\
{[\mathrm{mm}]}\end{array}$ & $\begin{array}{c}D_{\max } \\
{[\mathrm{mm}]}\end{array}$ & $\begin{array}{c}m \\
{[\mathrm{mg}]}\end{array}$ \\
\hline GG50 1 & 8.27 & 5.05 & 5.07 & 17.2 \\
GG50 2 & 8.30 & 5.05 & 5.08 & 16.5 \\
GG50 3 & 8.20 & 5.07 & 5.08 & 17.0 \\
GG50 4 & 8.18 & 5.03 & 5.05 & 17.3 \\
GG50 5 & 8.31 & 5.10 & 5.14 & 17.0 \\
\hline
\end{tabular}

TABle 8. Dimensions of GG samples with $50 \mathrm{wt} \%$ $\mathrm{BAG}$ for the tensile test under wet conditions.

\begin{tabular}{ccccc}
\hline Sample & $\begin{array}{c}h \\
{[\mathrm{~mm}]}\end{array}$ & $\begin{array}{c}D_{\min } \\
{[\mathrm{mm}]}\end{array}$ & $\begin{array}{c}D_{\max } \\
{[\mathrm{mm}]}\end{array}$ & $\begin{array}{c}m \\
{[\mathrm{mg}]}\end{array}$ \\
\hline GG70 1 & 8.61 & 4.93 & 4.96 & 23.0 \\
GG70 2 & 8.86 & 4.91 & 4.94 & 23.6 \\
GG70 3 & 8.63 & 4.93 & 5.00 & 24.2 \\
GG70 4 & 8.91 & 4.97 & 5.10 & 24.4 \\
GG70 5 & 9.12 & 4.94 & 5.00 & 24.5 \\
\hline
\end{tabular}

TABle 10. Dimensions of GG samples with $70 \mathrm{wt} \%$ BAG for the tensile test under dry conditions.

\begin{tabular}{ccccc}
\hline Sample & $\begin{array}{c}h \\
{[\mathrm{~mm}]}\end{array}$ & $\begin{array}{c}D_{\min } \\
{[\mathrm{mm}]}\end{array}$ & $\begin{array}{c}D_{\max } \\
{[\mathrm{mm}]}\end{array}$ & $\begin{array}{c}m \\
{[\mathrm{mg}]}\end{array}$ \\
\hline GG70 1 & 8.20 & 5.09 & 5.15 & 22.6 \\
GG70 2 & 8.34 & 5.10 & 5.15 & 23.2 \\
GG70 3 & 8.26 & 4.93 & 4.99 & 22.2 \\
GG70 4 & 8.24 & 4.97 & 5.01 & 23.3 \\
GG70 5 & 8.25 & 5.05 & 5.07 & 24.7 \\
\hline
\end{tabular}

TABle 12. Dimensions of GG samples with $70 \mathrm{wt} \%$ BAG for the tensile test under wet conditions.

scaffold synthetization, whereas the wet conditions simulated physiological environment of human body using artificial plasma with the content listed in Tab. 13 Dry samples were loaded at room temperature $\left(22^{\circ} \mathrm{C}\right)$. The samples placed in the bioreactor chamber were fully immersed in the solution with temperature $37 \pm 2{ }^{\circ} \mathrm{C}$. Because of permeability (required for transport of nutrients) of the material, full saturation by simulated body fluid was used during the test. Loading platen displacement was set to approximately $1000 \mathrm{\mu m}$ which corresponds to $\approx 11-12 \%$ deformation sufficient to induce some observable damage to the samples' microstructure 13, 14. Loading rate was set to $2 \mu \mathrm{ms}^{-1}$ yielding quasi-static strain rate $\approx 2 \cdot 10^{-4} \mathrm{~s}^{-1}$. The force and position was read-out with the sampling frequency $50 \mathrm{sps}$.

\begin{tabular}{ll}
\hline Natrii chloridum & $5.26 \mathrm{~g} / 1$ \\
Kalii chloridum & $0.37 \mathrm{~g} / 1$ \\
Magnesii chloridum hexahydricum & $0.30 \mathrm{~g} / 1$ \\
Natrii acetas trihydricus & $3.68 \mathrm{~g} / 1$ \\
Natrii gluconas & $5.02 \mathrm{~g} / 1$ \\
\hline
\end{tabular}

TABle 13. Content of the artificial plasma. 


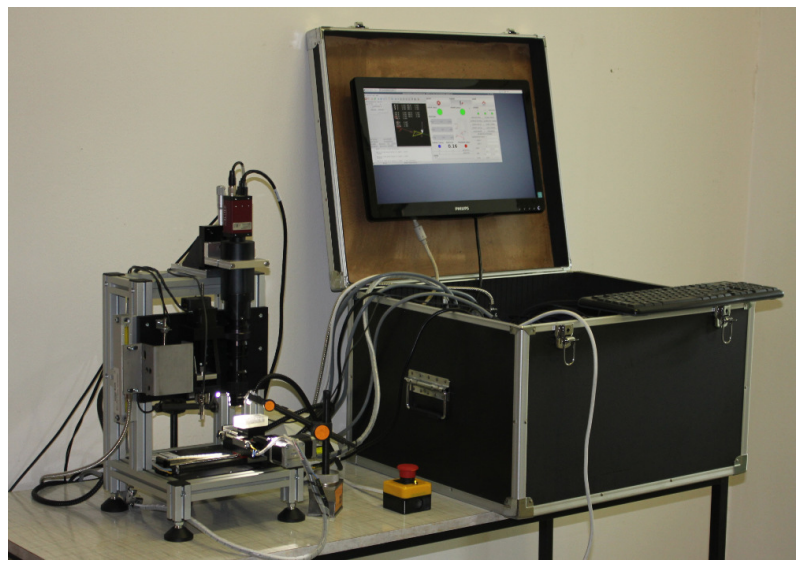

Figure 1. Custom designed micro-loading device with control unit.

\subsection{INSTRUMENTATION}

The in-house developed loading device (depicted in Fig. 11 for low-force indentation was adapted for both tensile and compression testing. For the indentation, the device was designed using the stiff modular aluminium $(30 \times 30 \mathrm{~mm}$ hollow profiles $)$ frame bearing the following components: (i) two motorized axes KK40 (HIWIN, Japan) for sample positioning accuracy $10 \mu \mathrm{m}$, (ii) loading axis based on linear stage MGW12 (HIWIN, Japan), and (iii) linear actuator 43-series (Haydon Kerk, USA) with positioning full-step resolution $3 \mu \mathrm{m}$ with mounting for U9B/C series (HBM, Germany) load-cell. This axis was upgraded using the same series linear actuator with positioning full-step resolution $1.5 \mu \mathrm{m}$, encoder with resolution $0.5 \mu \mathrm{m}$, and U9B/C load cell with nominal force $50 \mathrm{~N}$.

For the testing under the wet conditions, the device was equipped with a custom designed bioreactor (see Fig. 2). The bioreactor enables full control over flow-rate and temperature of the fluid used for the experiments. The fluid is pumped from a heated reservoir to a basin surrounding the samples and loading platens; circulation of the fluid is provided by a peristaltic pump with adjustable stream velocity.

The control unit of the experimental setup was designed specifically for controlling stepper- or servomotor based positioning devices. The control unit is also equipped with drivers, an I/O board for controlling peripheral devices (i.e. lights, etc.), and a unit for readout signals from load-cells. The used drivers are capable of microstepping up to 64 microsteps per steps to achieve a maximum possible smoothness of motion, when stepper motors are used for the experiments.

\subsection{STRAIN CALCULATION}

The investigated material was expected to exhibit very low stiffness, which, coupled with high porosity and suboptimal geometry of the samples, induces high potential for significant boundary effects (i.e. localized plastic deformation of the sample near the contact with the loading platens) yielding yielding low reliability

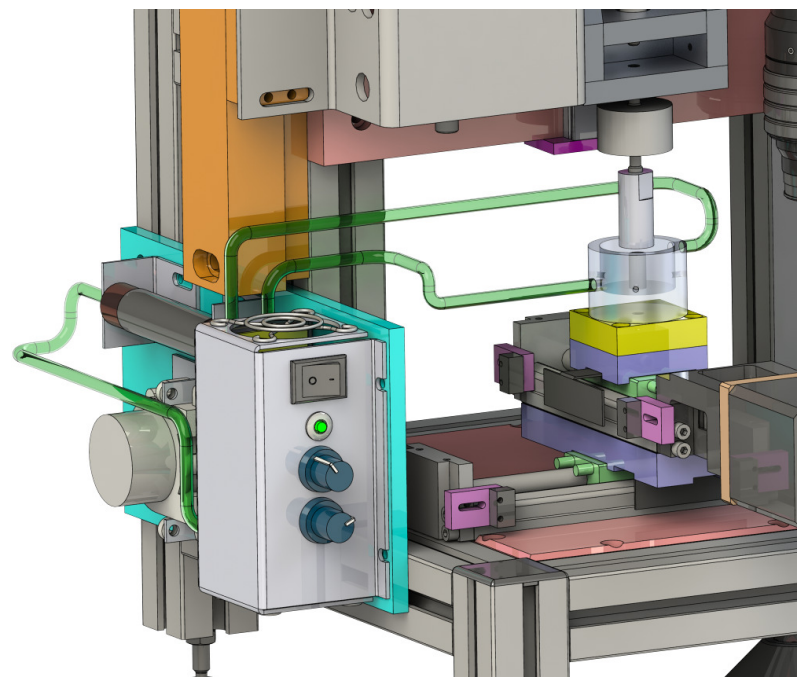

FiguRE 2. Visualization of bioreactor mounted on loading device.

of strain evaluation based on displacement of loading platens.

The accuracy of the presented measurements was reduced due to geometrical properties of the samples, the type of boundary conditions during experiments, and also by very low stiffness of the material. Currently, the production process of the GG-BAG samples does not allow to produce cylindrical samples too reliably. The diameter of the specimens varied in average by $\pm 100 \mu \mathrm{m}$, the loaded faces were rough and not planparallel. Furthermore, the character of the material, particularly its brittleness that is making it prone to severe damage during any type of preparation procedures, made machining of the samples impossible.

Thus, the non-contact optical displacement measurement was employed instead of calculations based on the known position of the loading platens. The strains were evaluated from optically acquired displacements using the digital image correlation (DIC) method. This method is based on the comparison of differences within the sequence of the deforming object images. When the image with identifiable texture is divided to subsets, the center coordinates $\left(x^{\prime}, y^{\prime}\right)$ of arbitrary subsets in a subsequent image are given by:

$$
\begin{aligned}
& x^{\prime}=x+u+\frac{\partial u}{\partial x} \Delta x+\frac{\partial u}{\partial y} \Delta y \\
& y^{\prime}=y+v+\frac{\partial v}{\partial x} \Delta x+\frac{\partial v}{\partial y} \Delta y
\end{aligned}
$$

where $u$ and $v$ are the displacements of the subset centroid in the $X$ and $Y$ directions respectively. $\Delta x$ and $\Delta y$ represent the distances from the centroid of the sub-image to the point $x$ and $y$. This enables to create any arbitrary correlation pattern on the investigated surface, including a matrix for full-field displacement tracking.

Here, the matrix of correlation points for full field measurements was constructed on every measured sample and paths of the correlation points were observed for 


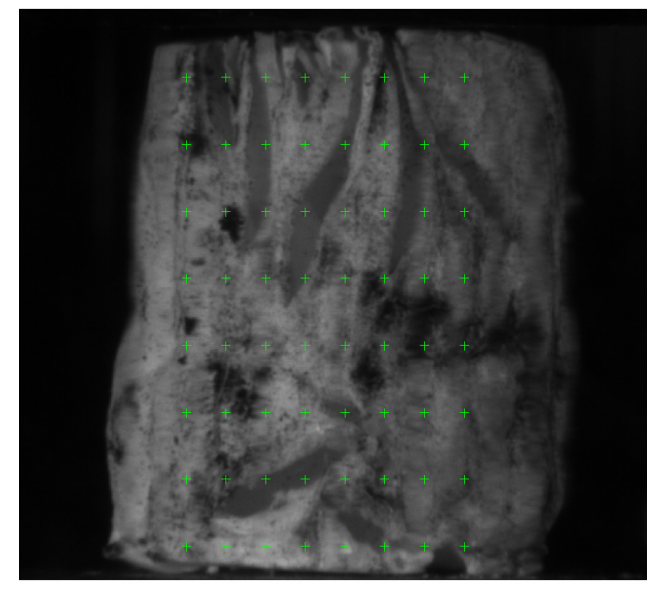

FIGURE 3. Surface of well manufactured sample with artificial patters and grid of correlation points for optical strain measurement.

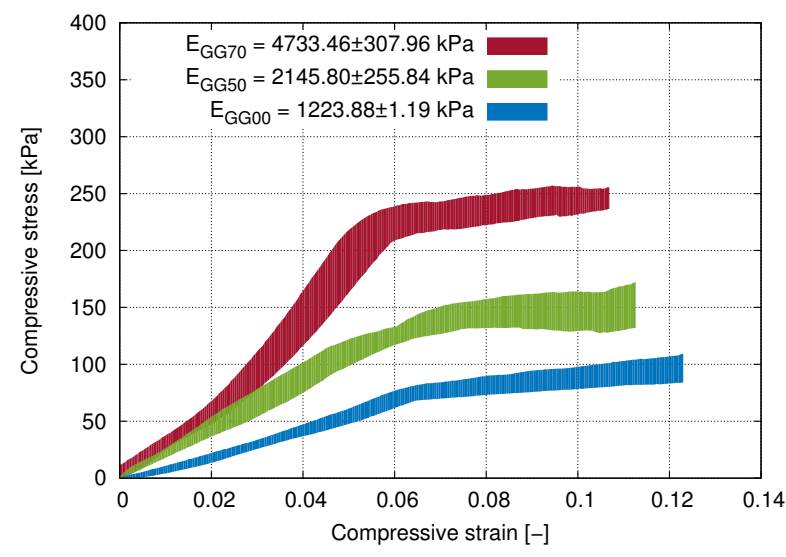

Figure 5. Stress-strain curves envelope dry scaffolds under the compressive loading.

calculating local deformations over the whole image sequence using the Lucas-Kanade tracking algorithm [15]. Using the obtained data, strain fields were derived and used for the calculation of stress-strain relations.

The full-field optical strain measurement of the wet samples placed in the fluid basin was not possible with the existing setup. Therefore, only comparative measurements on the dry pure GG samples and GG with $50 \mathrm{wt} \%$ BAG were performed. Here the average displacement of the bottom and top line of the correlation points (see Fig. 3) was used for strain calculation together with the encoder output. The resulting stressstrain curves of two compressive experiments are nearly identical in the elastic region. The strain measurement using the encoder signal can be considered acceptable only for such a measurement that can be seen in the comparative stress-strain diagrams depicted in Fig. 4 .

\subsection{Stress CALCUlation}

The stress $\sigma$ in all experimental analyses was considered as engineering stress obtained using:

$$
\sigma=\frac{F}{A_{c}}
$$

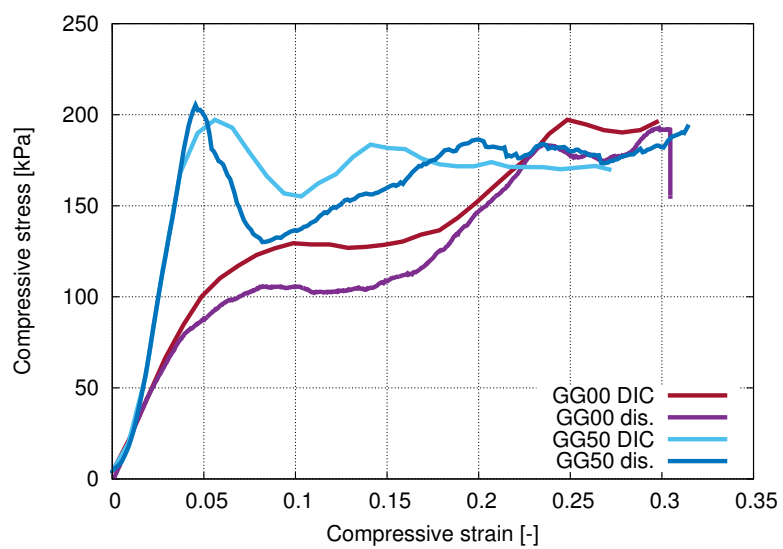

FiguRE 4. Stress-strain curves of two samples (pure GG in blue and $50 \mathrm{wt} \%$ BAG content in red) subjected to compressive loading under dry condition obtained from optical measurement and encoder signal.

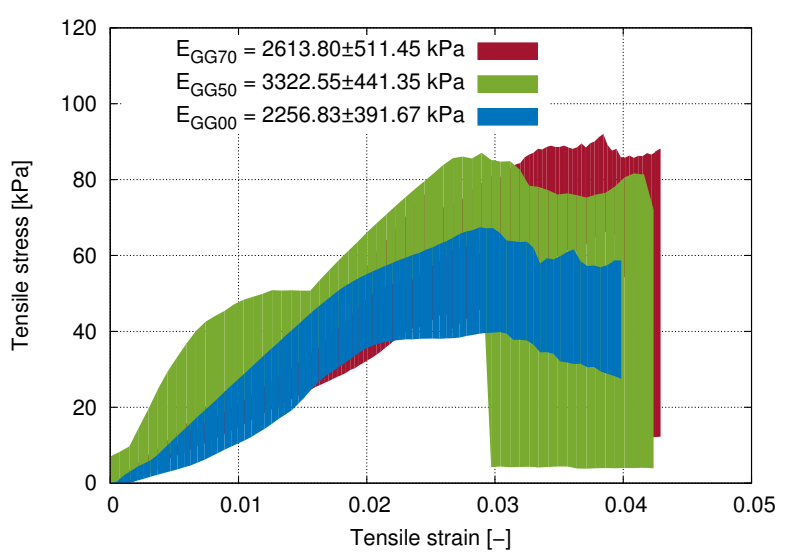

FiguRE 6. Stress-strain curves envelope of dry scaffolds under the tensile loading.

where $A_{c}$ is the cross-sectional area of the specimen calculated from the minimal sample diameter measured before deformation. The force $F$ was acquired by the load-cell. For the purpose of stress calculations, there were considered the ideally cylindrical samples neglecting all geometrical irregularities.

\section{Results}

Material properties and the deformation behaviour of the pure GG scaffold and the GG-BAG reinforced scaffold with $50 \mathrm{wt} \%$ and $70 \mathrm{wt} \%$ the BAG content were studied during the tensile and compression tests under the dry and wet conditions. Five experiments for each type of material, ambient conditions, and loading mode were performed. The stress-strain curves for each experimental batch are presented in Figs. 58. Young's modulus was calculated using the linear regression applied on the elastic part of the stress-strain diagrams. Regression error $R$ was calculated using:

$$
R=\sqrt{\frac{\sum_{i=1}^{n}\left(\sigma_{i}-\hat{\sigma}_{i}\right)}{n}},
$$




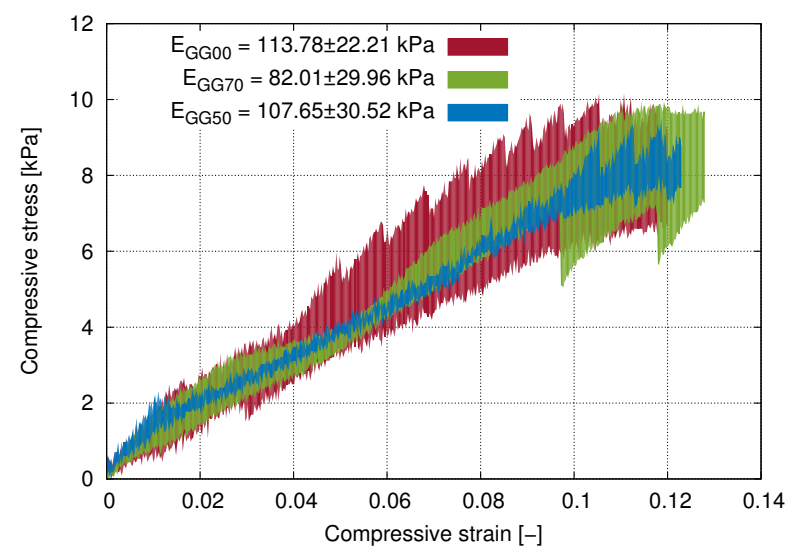

FiguRE 7. Stress-strain curves envelope wet scaffolds under the compressive loading.

\begin{tabular}{ccc}
\hline Sample & $E[\mathrm{kPa}]$ & $\sigma_{Y}[\mathrm{kPa}]$ \\
\hline GG00 1 & $1194.32 \pm 4.16$ & 61.52 \\
GG00 2 & $1479.81 \pm 6.27$ & 76.65 \\
GG00 3 & $1146.19 \pm 4.77$ & 88.51 \\
GG00 4 & $1119.64 \pm 5.26$ & 56.71 \\
GG00 5 & $1179.43 \pm 3.07$ & 62.28 \\
\hline Average & $1223.88 \pm 1.19$ & $69.14 \pm 13.14$ \\
\hline
\end{tabular}

TABLE 14. Elastic properties and yield stresses of pure GG samples for the compression test under dry conditions.

\begin{tabular}{cr}
\hline Sample & \multicolumn{1}{c}{$E[\mathrm{kPa}]$} \\
\hline GG00 1 & $88.58 \pm 0.14$ \\
GG00 2 & $119.50 \pm 0.15$ \\
GG00 3 & $126.15 \pm 0.14$ \\
GG00 4 & $93.57 \pm 0.14$ \\
GG00 5 & $141.08 \pm 0.14$ \\
\hline Average & $113.78 \pm 22.21$ \\
\hline
\end{tabular}

TABLE 16. Elastic properties of pure GG samples for the compression test under wet conditions.

where $\hat{\sigma}$ represent the calculated values of $\sigma$. For the yield stress $\sigma_{\mathrm{Y}}$ evaluation, the Christensen [16] second derivation criteria was used:

$$
\sigma_{\mathrm{Y}}=\sigma \quad \text { at } \quad\left|\frac{\mathrm{d}^{2} \sigma}{\mathrm{d} \epsilon^{2}}\right|=\max .
$$

For noise reduction, significantly distorting resulting derived function, a rolling average filter was computed from five values as:

$$
\sigma_{\mathrm{n}_{\mathrm{a}}}^{\prime}=\frac{\sigma_{\mathrm{n}-2}^{\prime}+\sigma_{\mathrm{n}-1}^{\prime}+\sigma_{\mathrm{n}}^{\prime}+\sigma_{\mathrm{n}+1}^{\prime}+\sigma_{\mathrm{n}+2}^{\prime}}{5} .
$$

The calculated Young's modulus, regression error, presented as $E \pm R$ and the yield stresses $\sigma_{Y}$ are listed in Tabs. 1425 together with mean values of each set of measurements and standard deviation of such calculated values. The yield stresses were presented only

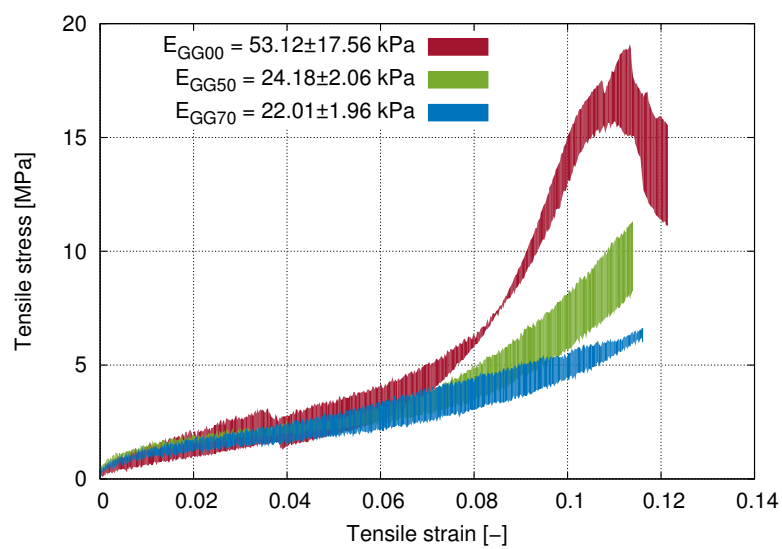

FiguRE 8. Stress-strain curves envelope of wet scaffolds under the tensile loading.

\begin{tabular}{lcc}
\hline Sample & $E[\mathrm{kPa}]$ & $\sigma_{Y}[\mathrm{kPa}]$ \\
\hline GG00 1 & $2164.31 \pm 0.92$ & 36.18 \\
GG00 2 & $2259.77 \pm 0.62$ & 45.83 \\
GG00 3 & $2915.55 \pm 1.10$ & 67.12 \\
GG00 4 & $2036.73 \pm 0.40$ & 48.78 \\
GG00 5 & $1906.54 \pm 0.42$ & 45.18 \\
\hline Average & $2256.58 \pm 391.67$ & $48.62 \pm 11.36$ \\
\hline
\end{tabular}

TABLE 15. Elastic properties and yield stresses of pure GG samples for the tensile test under dry conditions.

\begin{tabular}{cc}
\hline Sample & $E[\mathrm{kPa}]$ \\
\hline GG00 1 & $56.34 \pm 0.84$ \\
GG00 2 & $33.40 \pm 0.20$ \\
GG00 3 & $36.38 \pm 0.41$ \\
GG00 4 & $69.07 \pm 0.94$ \\
GG00 5 & $70.43 \pm 0.95$ \\
\hline Average & $53.12 \pm 17.56$ \\
\hline
\end{tabular}

TABLE 17. Elastic properties of pure GG samples for the tensile test under wet conditions.

for the dry samples. In case of testing under the wet conditions, the loadcell output signal-to-noise was too low for the yield stress evaluation. All obtained results in the form of the enveloped strain-stress curves are plotted in Figs. 578

\section{CONCLUSiOn AND Discussion}

The GG-BAG samples with different fraction of the reinforcing BAG particles were subjected to optically evaluated uni-axial measurements under both dry and wet conditions. It was found out that the ambient environment has significant influence on the mechanical response of the material and measured properties of the dry and wet scaffolds were apparently different.

The scaffolds wetted by a synthetic plasma solution exhibited radical loss of stiffness while the elastic modulus decreased more than ten times. In addition, 


\begin{tabular}{ccc}
\hline Sample & $E[\mathrm{kPa}]$ & $\sigma_{Y}[\mathrm{kPa}]$ \\
\hline GG50 1 & $2100.57 \pm 0.46$ & 132.52 \\
GG50 2 & $2066.95 \pm 3.01$ & 127.33 \\
GG50 3 & $1818.36 \pm 1.57$ & 93.46 \\
GG50 4 & $2520.59 \pm 1.01$ & 132.68 \\
GG50 5 & $2222.56 \pm 0.42$ & 140.42 \\
\hline Average & $2145.81 \pm 255.84$ & $125.28 \pm 18.39$ \\
\hline
\end{tabular}

TABLE 18. Elastic properties and yield stresses of GG samples with $50 \mathrm{wt} \% \mathrm{BAG}$ for the compression test under dry conditions.

\begin{tabular}{cr}
\hline Sample & \multicolumn{1}{c}{$E[\mathrm{kPa}]$} \\
\hline GG50 1 & $81.45 \pm 0.14$ \\
GG50 2 & $131.88 \pm 0.13$ \\
GG50 3 & $70.84 \pm 0.14$ \\
GG50 4 & $113.89 \pm 0.28$ \\
GG50 5 & $140.22 \pm 0.20$ \\
\hline Average & $107.65 \pm 30.52$ \\
\hline
\end{tabular}

TABLE 20. Elastic properties of GG samples with $50 \mathrm{wt} \%$ BAG for the compression test under wet conditions.

the values of the peak force, which was measured during the tests and averaged at $\approx 0.5 \mathrm{~N}$, may be influenced by the load-cell nonlinearity and low signal-to-noise ratios.

Therefore, it wasn't possible to evaluate the yield stress properly using the acquired load-cell signal.

All compressed wet samples showed very similar deformation behaviour. The standard deviation for the samples from one group was higher than the effects of the BAG reinforcement. Unexpectedly, the results obtained for the wet samples subjected to tensile loading showed higher elastic modulus and ultimate stresses of the pure GG samples. This can be attributed to the fact that, on the microstructural level, the BAG particles disrupt integrity of the wet gellan gum. In case of the dry samples subjected to compression loading, a significant reinforcement effect of the BAG was observed. The values of elastic modulus and yield stresses are two and three times higher for $50 \mathrm{wt} \%$ and $70 \mathrm{wt} \%$ BAG improved samples respectively.

During the tensile loading, the elastic properties of the samples were very similar independently on the content of the BAG reinforcing particles, but higher reinforcement increased the measured ultimate stress. The yield stresses of both the $50 \mathrm{wt} \%$ and $70 \mathrm{wt} \%$ BAG were $20 \%$ compared to the pure GG samples. The samples loaded in tension were also able to resist the deformation up to $4 \%$.

Possibilities of experimental infrastructure for the testing of the newly synthetized GG based scaffolds was successfully demonstrated. The most limiting part of the experimental setup is the loadcell signal-to-noise ratio at the desired loading level in case of the wet

\begin{tabular}{ccc}
\hline Sample & $E[\mathrm{kPa}]$ & $\sigma_{Y}[\mathrm{kPa}]$ \\
\hline GG50 1 & $5805.60 \pm 0.30$ & 40.15 \\
GG50 2 & $3137.46 \pm 0.23$ & 85.71 \\
GG50 3 & $2520.69 \pm 0.27$ & 67.99 \\
GG50 4 & $2157.34 \pm 0.31$ & 63.40 \\
GG50 5 & $2991.67 \pm 1.02$ & 85.25 \\
\hline Average & $3322.55 \pm 1441.35$ & $68.50 \pm 18.75$ \\
\hline
\end{tabular}

TABLE 19. Elastic properties and yield stresses of GG samples with $50 \mathrm{wt} \%$ BAG for the tensile test under dry conditions.

\begin{tabular}{cc}
\hline Sample & $E[\mathrm{kPa}]$ \\
\hline GG50 1 & $24.40 \pm 0.09$ \\
GG50 2 & $27.15 \pm 0.08$ \\
GG50 3 & $24.28 \pm 0.08$ \\
GG50 4 & $23.71 \pm 0.08$ \\
GG50 5 & $21.37 \pm 0.08$ \\
\hline Average & $24.18 \pm 2.06$ \\
\hline
\end{tabular}

TABLE 21. Elastic properties of GG samples with $50 \mathrm{wt} \% \mathrm{BAG}$ for the tensile test under wet conditions.

samples and generally suboptimal geometrical characteristics of the samples inducing shear stresses during loading. For more complex investigation including the detailed analysis of the deforming microstructure, the time-lapse radiographical methods will be used [17, 18.

\section{ACKNOWLEDGEMENTS}

The research was supported by Grant Agency of the Czech Technical University in Prague (grant no. SGS15/225/OHK2/3T/16), by European Regional Development Fund in frame of the project Com3D-XCT (ATCZ-0038) in the Interreg V-A Austria-Czech Republic programme and by institutional support RVO: 68378297 . The Slovenian Research Agency is acknowledged for its financial support of the PhD study of the co-author, Ms. Ana Gantar (PR-03770).

\section{REFERENCES}

[1] W. H. Organization. World health statistics. WHO Press, 2015.

[2] W. H. Organization. Global Recommendations on Physical Activity for Health. WHO Press, Switzerland, 2010.

[3] A. R. Vaccaro, K. Chiba, J. G. Heller, et al. Bone grafting alternatives in spinal surgery. The Spine Journal 2(3):206 - 215, 2002. DOI:10.1016/S1529-9430(02)00180-8

[4] A. R. Amini, C. T. Laurencin, S. P. Nukavarapu. Bone tissue engineering: Recent advances and challenges. Critical Reviews in Biomedical Engineering 40(5):363-408, 2012. DOI:10.1615/CritRevBiomedEng.v40.i5.10

[5] L. Polo-Corrales, M. Latorre-Esteves, J. Ramirez-Vick. Scaffold design for bone regeneration. Journal of Nanoscience and Nanotechnology 14(1):15-56, 2014. DOI:10.1166/jnn.2014.9127 


\begin{tabular}{ccc}
\hline Sample & $E[\mathrm{kPa}]$ & $\sigma_{Y}[\mathrm{kPa}]$ \\
\hline GG70 1 & $4857.36 \pm 0.34$ & 208.05 \\
GG70 2 & $4441.11 \pm 0.38$ & 204.68 \\
GG70 3 & $5058.45 \pm 0.32$ & 202.55 \\
GG70 4 & $4371.74 \pm 4.38$ & 224.20 \\
GG70 5 & $4938.64 \pm 0.23$ & 213.25 \\
\hline Average & $4733.46 \pm 307.96$ & $210.55 \pm 8.63$ \\
\hline
\end{tabular}

TABLE 22. Elastic properties and yield stresses of GG samples with $70 \mathrm{wt} \% \mathrm{BAG}$ for the compression test under dry conditions.

\begin{tabular}{cc}
\hline Sample & $E[\mathrm{kPa}]$ \\
\hline GG70 1 & $134.42 \pm 0.12$ \\
GG70 2 & $63.56 \pm 0.07$ \\
GG70 3 & $79.59 \pm 0.07$ \\
GG70 4 & $67.37 \pm 0.08$ \\
GG70 5 & $65.13 \pm 0.07$ \\
\hline Average & $82.01 \pm 29.96$ \\
\hline
\end{tabular}

TABLE 24. Elastic properties of GG samples with $70 \mathrm{wt} \%$ BAG for the compression test under wet conditions.

[6] E. R. Morris, K. Nishinari, M. Rinaudo. Gelation of gellan - a review. Food Hydrocolloids 28(2):373 - 411, 2012. DOI:10.1016/j.foodhyd.2012.01.004

[7] D. F. Coutinho, S. V. Sant, H. Shin, et al. Modified gellan gum hydrogels with tunable physical and mechanical properties. Biomaterials 31(29):7494 - 7502, 2010. DOI:http://dx.doi.org/10.1016/j.biomaterials.2010.06.035

[8] A. Gantar, L. Da Silva, J. Oliveira, et al. Nanoparticulate bioactive-glass-reinforced gellan-gum hydrogels for bonetissue engineering. Materials Science and Engineering $C$ 43:27-36, 2014. DOI:10.1016/j.msec.2014.06.045

[9] D. Hoikhman, Y. Sela. Gellan gum based oral controlled release dosage forms- a novel platform technology for gastric retention, 2005. WO Patent App. PCT/IL2004/000,654.

[10] M. Bououdina. Emerging Research on Bioinspired Materials Engineering. IGI Global, 2016. DOI:10.4018/978-1-4666-9811-6

[11] J. T. Oliveira, L. Martins, R. Picciochi, et al. Gellan gum: A new biomaterial for cartilage tissue engineering applications. Journal of Biomedical Materials Research Part A 93A(3):852-863, 2010. DOI:10.1002/jbm.a.32574

[12] N. Drnovšek, S. Novak, U. Dragin, et al. Bioactive glass enhances bone ingrowth into the porous titanium coating on orthopaedic implants. International Orthopaedics 36(8):1739-1745, 2012. DOI:10.1007/s00264-012-1520-y.

\begin{tabular}{ccc}
\hline Sample & $E[\mathrm{kPa}]$ & $\sigma_{Y}[\mathrm{kPa}]$ \\
\hline GG70 1 & $2565.45 \pm 0.68$ & 83.81 \\
GG70 2 & $3087.56 \pm 0.22$ & 56.13 \\
GG70 3 & $2847.83 \pm 1.07$ & 68.55 \\
GG70 4 & $1761.72 \pm 0.67$ & 65.98 \\
GG70 5 & $2806.60 \pm 1.06$ & 88.45 \\
\hline Average & $2613.83 \pm 511.06$ & $70.78 \pm 13.30$ \\
\hline
\end{tabular}

TABLE 23. Elastic properties and yield stresses of GG samples with $70 \mathrm{wt} \%$ BAG for the tensile test under dry conditions.

\begin{tabular}{cc}
\hline Sample & $E[\mathrm{kPa}]$ \\
\hline GG70 1 & $22.76 \pm 0.08$ \\
GG70 2 & $23.44 \pm 0.08$ \\
GG70 3 & $20.90 \pm 0.08$ \\
GG70 4 & $21.14 \pm 0.10$ \\
GG70 5 & $22.70 \pm 0.07$ \\
\hline Average & $22.19 \pm 1.10$ \\
\hline
\end{tabular}

TABLE 25. Elastic properties of GG samples with $70 \mathrm{wt} \% \mathrm{BAG}$ for the tensile test under wet conditions.

[13] J. Garrison, C. Slaboch, G. Niebur. Density and architecture have greater effects on the toughness of trabecular bone than damage. Bone 44(5):924-929, 2009. DOI:10.1016/j.bone.2008.12.030

[14] O. Jiroušek, P. Zlámal, D. Kytýř, M. Kroupa. Strain analysis of trabecular bone using time-resolved x-ray microtomography. Nuclear Instruments and Methods in Physics Research, Section A: Accelerators, Spectrometers, Detectors and Associated Equipment 633(SUPPL.

1):S148-S151, 2011. DOI:10.1016/j.nima.2010.06.151

[15] B. D. Lucas, T. Kanade. An iterative image registration technique with an application to stereo vision. In Proceedings of the 7th International Joint Conference on Artificial Intelligence - Volume 2, IJCAI'81, pp. 674-679. Morgan Kaufmann Publishers Inc., San Francisco, CA, USA, 1981.

[16] R. M. Christensen. Observations on the definition of yield stress. Acta Mechanica 196(3):239-244, 2008. DOI:10.1007/s00707-007-0478-0.

[17] I. Kumpová, D. Vavř́k, T. Fíla, et al. High resolution micro-ct of low attenuating organic materials using large area photon-counting detector. Journal of Instrumentation 11(02):C02003, 2016. DOI:10.1088/1748-0221/11/02/C02003.

[18] D. Kytýř, T. Doktor, O. Jiroušek, et al. Deformation behaviour of a natural-shaped bone scaffold. Materiali in Tehnologije 50(3):301-305, 2016. DOI:10.17222/mit.2014.190. 